\section{ABDOMINAL EMERGENCIES.}

The Substance of Two Lectures of the Post-Graduate Course, NeWCastle. on-Tyne.

BY

RUTHERFORD MORISON,

PROFESSOR OF BURGERY, ONIVERSITY OF DURHAM (NEWCASTLE).

Seventeen years ago, in an address on abdominal emergencies given to the Middlesbrough Medical Society (Surgical Contributions, p. 480), I said :

Future progress in abdominal emergencies is to be gought for in prompt treatment, and the most important advances depend upon your care and skill; they are not to be expected from the ingenuity and daring of mere operators but from more
prompt diagnosis and more vigorous action on the part of the general practitioner.

Here is a list of the twenty-six cases in the Royal Victoria Infirmary to-day:

\begin{tabular}{cccccc}
$\begin{array}{c}\text { Acute appendicitis } \\
\text { Appendix abscess }\end{array} \ldots$ & $\ldots$ & $\ldots$ & $\ldots$ & $\mathbf{8}$ \\
Gall stones, acuto $\ldots$ & $\ldots$ & $\ldots$ & $\ldots$ & 7 \\
Ruptured duodenal uicer & $\ldots$ & $\ldots$ & $\ldots$ & 3 \\
Intestiual obstruction, acu.tc & $\ldots$ & $\ldots$ & 5 \\
Total & $\ldots$ & $\ldots$ & $\ldots$ & $\ldots$ & 3 \\
\hline
\end{tabular}

Of these, one, a case of dnodeual ulcer, died from septic peritonitis of fifty-three hours' daration. He was moribund when admitted.

Sixteen doctors answered, by letters, questions concerning these patients, and I am indebted to them for much valuable information given on short notice.

The Abdominal Facies.

In every caso you will be sent for because the patient has abdominal pain. The first question to be answered is whether this is duo to some serious cause or not, and that can often be decided if the patient is seen in the early stage after a single lcols. Doctors are students of the expression of the emotions, and, if they are wise, cultivate the faculty of careful observation of every detail. It is only because observation of the expression and conduct of patients is so commonplace that this has not received the attention due to it, though it is only fair to noto that the "abdominal facies" is emphasized in some recent surgical literature.

One of the sayings of the late Dr. Murplyy of Sunder. land was that when he entered a woman's room after an abdominal operatien and saw her hand leaving her hair he knew that there was nothing very serious the matter with her, however loud her complaints. Such an observation is based upon a knowledge of human nature. A dcsperately ill patient.is careless of the ordinary small refinements of life, and looks like it.

\section{InItial Shock.}

The second point helpful in arriving at an opinion is a history of the illness. At the commencement of every serious abdominal emergency there is "shock," and this produces effects so obvious as to alarm the patient's friends. They "noticed the change and they thought something serious had happened." It is well to listen to their story, beeause in some cases "shock" very quickly disappears and a stage of reaction follows, when recovery may appear to be so complete as to deceive the most wary. This occurs even in such serious and hopeless conditions as lacerations of the hollow viscera by injury and perforations of gastro-intestival ulcers. ${ }^{1}$ To impress this upon students I used to relate to them the story told at a coroner's inquest on a famous footballer. During the game on a Saturdsy he was forcibly struck in the abdomen by the bent knee of an opponent, fell down at once looking very bad, and was carried to the club-house "winded." He was immediately seen by a doctor, but in two hours had so far recovered that he was able to be taken home, and everyone thought he was little the worse. On Tuesday lue was very ill with "inflammation of the bowels," and was sent to the cottage hospital, where he died on rhursday. Post-mortem examination showed that the small bowel had been torn across and had leaked, and that death was due to peritonitis. Think of it, and remember that similar cases are still occurring every week. A kick from a horse, a blow from a cart shaft, some localized force suddeuly applied to the abdominal wall, ruptures the intestine. Operation within six hours would save 90 per cent. of these patients; the policy of "wait and see" allows 90 per cent. of them to die. The reason why they do not all die was made the subject of experiment by Hamilton Drummond in France. He cut the intestine of animals and replaced them open. For many hours the intestine lay where it was placed and expelled none of its contents. Natural repair followed and the animals recorered-because their intestine was paralysed from the injury. In soldiers shot through the abdomen he found a similar paralytic condition of the intestine, with little extravasation of its contents.

In the reactive, or second, stage the patient may look and feel so much better that it seems almost impossible that there are serious results to follow. Now is the time when diagnosis is most difficult, and often most important, and it may be impossible to answer the first question wo have to ask ourselves-namely, Whether is the condition a serious one or not? (Case I.)

\section{History as to Pain.}

The third clue is to be found in a study of the history of that pain which was tho cause of your attendance. How did it commence? How did it progress? Was it preceded by any warning? Have similar attaclss occurred before?

The causes of abdominal pain are special to the abdomen. All the viscera are insensitive to ordinary pain stimuli. They can be cut or burned or sutured and no sensation results. On the other hand, the parietal peritoneum is exquisitely sensitive, and stimulation of it produces the first type of pain; the hollow viscera respond strongly to intravisceral irritation, especially such as is produced by foreign bodies phus infection, and to tension, and this is the second cause of pain; the mesentery and attachments of the viscera are painful when dragged upon, and this is the cause of a third type of pain.

Irritation of the Peritoneum.

A countryman was going home at the end of a day's work, and when within a hundred yards of his cottage jumped over a low railing. In the act of jumping he was suddenly seized with a pain in his stomach so severe that he fell, and thought he was going to die. For an hour he lay where he fell, entirely conscious but feeling that he had to lie still, and that he dare nat make even the effort to shout for help. He was carried home, seen by a doctor (who found him cold and collapsed), and sent to the infirmary on a stretcher in a guard's van. On arriving there be appeared to be very well, but there was some evidence from physical signs that he was not. His previous health had been good except that ho had had periodic attacks of "indigestion," but never serious pain before. Operation showed a perforated duodenal ulcer. Such a sudden serious pain suggests perforation of a hollow viscus, and the cause is irritation of the peritoneum by escaping visceral contents.

\section{Forcible Contraction of Unstriated Muscle.}

A young man got up at 5.30 in the morning to go to work, and felt some pain in his inside. He took a "good dose" of castor oil before going out. He went to his work on a tram car. The pain grew worse, and he vomited twice before reaching his destination, and was able, but doubled up and with diffculty, to wall to a signal cabin on the railway, where he gat down. During an hour there he vomited four times, and the pain was so bad that he could not help shouting and rolling about on the floor. On admission to hospital three hours later, he had frequent paroxysms of pain during which he shouted out like a woman in labour, and tossed about in bed. Previously he had had similar attacks, bat none so severe, and a dose of castor oil had always put him right before. Operation showed a loop of gut strangulated by an adherent Meckel's diverticulum. Such a pain, paroxysmal in character and severe enough to make the patient shout and roll about, suggests the forcible contraction of unstriated muscle, caused by increased intravisceral tension. Gall stones, stones in the pelvis of the kidney or ureter, and obstruction of the intestine are the most familiar examples of this variety of pain.

Dragging on the Mesentery (Torsion).

A young man was awakened by severe pain in his lower abdomen and right testicle which was partly undescended 
He felt faint, broke into a cold sweat, slept no more and vomited twice. In a few hours his testicle had swelled to the size of an orange, and pain continued till operation, seventy-two hours later. There was complete torsion of the spermatic cord and gangrene of the testicle. A similar condition is more common in women, when ovarian cysts twist their pedicles. In all of them, men and women, the final half twist has been preceded by others less severe, and this story also holds true of the similar condition called volvulus of the intestine. In all the pain is mainly due to forcible dragging on the mesentery.

The severity of pain, its method of onset, its character, its precedents and progress may tell a story sufficiently clear to aid in diagnosis.

\section{Rigidity of AbDominal WaLt.}

There is only one more point to which I need specially refer, $:$ nd as it concerns a physical sign it is of great importance.

What is the condition of the abdominal wall? Look at it. Does it move freoly, or does it move at all with re. spiration? If it moves freely, the abdominal condition is unlikely to be serious; if it does not move at all, peritonitis due to a ruptured viscus is suggested.

The joints and the abdomen present features in common. The same nerves supplying a joint innervate the muscles which move it; so that pain in a joint results in a protective contraction of the muscles which activate it. Visceral nerves are similarly related to the nerves supplying muscles which move the abdominal wall, and abdominal pain is accompanied by protective rigidity of the muscles overlying an intraperitoneal lesion.

Now feel the abdominal wall. If there is no tenderness no rigidity, and no underlying lump, a colic (forcible contraction of unstriated muscle) is the cause; a tender tumour, without considerable rigidity over it, is a looalized lesion connected with one of the intra-abdominal viscera; definite rigidity and tenderness point to inflammation of the peritoneum, and the more diffuse these are the inore serious the condition probably is.

\section{Intra-abdominal Hagmorrhage}

Another of the serious abdominal emergencies is due to intra-abdominal haemorrhage.

Blood is an irritant to the peritoneum, not so vicions as extravasated contents of the hollow viscera, but sufficient to cause pain, so that pain is usually the first symptom of intra-abdominal haemorrhage, whether it be caused by injury or not. The same shock, followed by reaction, is present as. in the conditions considered previously, but instead of developing symptoms of peritonitis, the third stage in intra-abdiominal haemorrhage is the result of loss of blood. Symptoms occur in the following sequence:

(1) A feeling of anxiety and weakness; (2) pallor of the visible mucous membranes and face; (3) thirst; (4) quickening and enfeeblement of the pulse; (5) a craving for more air ; (6) a cold, clammy skin, earliest appreciable on the forehead; (7) sighing, yawning, restlessness: (8) noises in the head and dimness of vision; (9) dilated pupils and syncope; (10) diminished percentage of haemo. globin in the blood.

These symptoms occurring after an abdominal injury suggest rupture of one of the solid viscera-liver, kidney, spleen; after operation, slipping of a ligature; without injury, and in a woman a ruptured ectopic gestation.

Operation, if done early enough and followed or preceded by blood transfusion, in the worst case's will save the majority from death.

\section{Treatment.}

Relief of his pain is what the patient demands, and so would any one of us; but before giving either a hypo.' dermic injection of morphine or any purgative it is essential to answer the question, Is the case serious or not? If no satisfactory answer can be found, no morphine or aperient must be given till the problem has been solved. Before leaving the patient count and note his pulse rate, and later count it again. A rise in the pulse rate is the most important sign of progressive.mischief, and in doubtful cases the pulse rate should be noted at least every hour.

Pathology teaches us that operation offers the only reasonable chance in an overwhelming majority of serious cases, and its chief objects, in the abdomen as everywhere else, are: (1) To arrest haemorrhare, (2) to remove or exclude a focus of disease, and (3) to deal with mechanical obstacles.

To prevent septic peritonitis, which can only be accom plished by removing or excluding the focus of inlection before widespread mischief has arisen, is the chief object of abdominal operation. It is possible in early cases of peritonitis to arrest further infection, but it must be recognized that recovery has been brought about by giving nature a chance. General peritonitis is the same deadly infection it always has been, and when fully developed, or when the cause of it cannot be dealt with, surgical opera tion has always done more harm than good. Surgeons are now beginning to realize that peritonitis resulting from acute gonococcal, pneumococcal, and pancreatic infections - conditions for which no satisfactory means of dealing with the focus of infection exist-may be made worse by operative interference, and that the best chance for these patients is to wait for localization, prepared to deal with an abscess if life should be prolonged for a sufficient time to allow of its development.

The moral of this knowledge is obvious, and I have preached the application of it in season, and perhaps out of it, for at least twenty-five years. As it is not yet universally applied, let me reiterate.

Every patient with a more than ordinary pain in the abdomen ought to be sent for observation, and, if needful, operation, to a properly equipped hospital without delay. A note as to the condition of the patient when first seen, and stating whether morphine has been given or withheld, should accompany him. It has been the custom with some medical men in this district to do this for years, and many of them can now boast that no patient of theirs has died as a result of an abdominal emergeucy.

The first portion of the time at our disposal has been occupied in discussing the most important problem to be solved-namely, Is the condition serious, or is it not? On the next occasion I shall deal with the differential diagnosis of cases.

\section{DIFEERENTIAL DIAGNOSIS.}

It has always to be remembered that abdominal pain may depend upon conditions not strictly surgical, and the advantage of a physician's co-operation should not be lost sight of.

The following is a list of the possibilities of which I have personal -and sometimes unfortunate-knowledge. They can be grouped into three classes:

1. Irritation of the lower six intercostal nerves, resulting from pneumonia, pleurisy (purulent or otherwise), pericarditis, herpes zoster, growths or caries of the vertebrae, locomotor ataxia, and hysteria, may produce abdominal pain and rigidity of the muscles. Acute inflammations in the chest, which are occasionally, in the early stages, accompanied by vomiting and pain referred to the abdomen are specially difficult to distinguish from the abdominal emergencies, and should not be forgotten.

2. General toxic conditions, such as arise from chronic kidney disease, diabetes, Addison's disease, Henoch's purpura, ptomaine poisoning, lead poisoning, typhoid fever, may each be introduced to your notice because of acute abdominal pain.

3. Abdominal conditions, such as pyelitis, kidney and ureter stones, tuberculous lymphatic glands, and especially acute dilatation of the stomach, may produce symptoms simulating those of peritonitis, and in women dysmenorrhoea may be mistaken for something worse.

So much has been made of the difficulties of diagnosis that it has become a fashion to teach, "Open the abdomen and see"; but this is a pernicious doctrine fatal to all progress, and sometimes to the patient. There are still doubts which can only be cleared up by operation, but they have become a steadily diminishing quantity as the result of more careful study of the problems to be solved. If a note be kept in every case of the pre-operative diagnosis, and later compared with the findings at the operation; an efficient stimulus to better work will be provided.

The most cominon cause of an abdominal emergency is appendicitis, and it is a good rule in diagnosis to consider the most likely thing first.

\section{Arpendicrisis.}

As usual your attendance has been asked for on account of abdominal pain. 
When the vermiform appendix is in its normal position, on the inner side of the cascum and pointing upwards to the spleen, and is acutely inflamed, the symptoms and signs are so definite that mistakes are now seldom made.

In the early stage a variable amount of shock is present, and the patient looks ill, but seldom dangerously so. A history of previous attaclss is frequently obtainable. The shock stage is quickly followed by reaction. The pain has of ten wakened the patient from sleep, and generally prevents any further rest on that same night. It is at first diffuse, and referred to the epigastrium or umbilicus, a few hours later settling to the right iliac fossa. Though often coming on quickly and very acute, it is never so sudden in onset or so severe as that produced by the rupture of a duodenal ulcer. In the early stages it may have periods ot intermission and exacerbation, due to the efforts of the inflamed appendix to empty itself of its contents (appendicular colic). The pain, like nearly all surgical pain, is due to tension, and the greater this is the more severe the pain. If the appendix cannot empty, tension gangrene of it quickly supervenes, and, as dead nerves convey no impulses, the acute pain disappears.

An acutely inflamed appendix which is draining into the caecum will prodace little pain until peritonitis develops.

Soon after the pain appears, vouniting comnences, and then follows a rise in temperature. Great stress has been attached to this sequence by Dr. Murphy of Chicago, as the most valuable part of the history in arriving at a jiagnosis.

The Physical Signs are: (1) Rigidity of the muscles covering (2) a tender spot in the right iliac fossa.

'The most dangerous and acute cases, if not seen in the carly stages, are often during the reaction stage most deceptive. The urgent early pain having disapr-ared, those who know no better are relieved of their anxiety tili the gangrenous appeudix, distended by highly infectious contents, ruptures into the peritoneum. During the gangrenous stage in these serious cases the only definite clues to diagnosis may be right iliac rigidity and tenderness, which do not disappear with the pain.

You may remember that of the fifteen cases of acute appendicitis in the infirmary on the day we last met seven were abscess cases. The explanation of this is generally to be found in the anatomical position of the appendix. If it is not in its normal position but in the sabcaecal pouch, or the pelvis, or lying in the gutter on the outer side of the caecum and ascending colon, the symptoms and sigus are less definite, and require more careful looking for. They can and ought to be found, because an appendix which has leaked refiects discredit upon someone, as the leak adds to the danger of an operation, and is followed by more severe complications and longer convalescence after it. Careful palpation of the abdomen or through the reetum will seldom fail to discover a specially tender area overlying the inflamod appendix.

The symptoms of inflammation everywhere are-(1) general, and (2) local. The geveral symptom is fever; the local : pain, redness, lieat, swelling, and loss of function, but the last four are not perceptible in appendicitis till the appendix has been exposed.

Consequently, in the most difficult cases sadden abdomival pain and a rise in temperaturo or a leuco. cytosis way be only symptous, and it is soldom wrong to make a diagnosis of appeudicitis when these are found together. The most frequent mistake made now is to think of a $B$. coli pyelitis as appendicitis, but the discovery of pus in the urine will help to clear this up.

The most serions cases are often attended at their commencenent by a riger; severe pain, repeated vomiting, and diarrhoea are al ways danger signals.

[Two coloured drawings were shown to illustrate the shock stage with a rea, tense, swollen appendix, and the stage of reaction, with complete gangrene of the appendix.]

CASE I. - Complete Gangrene of the Appendix.

This man, afed 39 admitted January 14th, 1920, had been awakened at 2 o'clook in the morning of Tuesday, January 13th, with pein all scross the abdomen above the navel. He stept no more that night, and yas so bad be "felt his end was up." At 10 k.m. on Tuesday vomiting commenced, and he vomited at least twelve times before Tuesday night, when the vomiting ceased. On Tuesias afternoon he began to feel feverigh, and alept none, or very little, dnring 'Plueadiny night. On Wednesday morning he was purged three to four times. After the purging the pain more as a feeling of soreness than of pain, and he was otherwise quite comfortable. When the doctor examined him he only elt tender on the right side.

The doctor saw him at 12.30 p.m. on Wednesday, and told him he had appendicitis and shonld go to the infirmary at once for an operation. When he was told this he got up, put his clothes on without help, and walked about the kitchen till the taxi came to drive him to the infirmary, a distance of 50 miles. He had no trouble on the journey, and wondered whell he felt so well whether the doctor was right in saying he had he felt so well whether the doctor was right in saying he had
appendicitis. He walked from the cab, got a ticket at the appendicitis. He walked from the cab, got a ticket at the
infirmary office, and proceeded into the ward without difficulty infirmary office, and proceeded into the ward without difficulty had never had any abdominal trouble before.

On admission his pulse was 98 , temperature $100^{\circ}$. There was some muscular rigidity in the right iliac fossa, and he was very ender over McBurney's point.

Operation was performed on Wednesday, Jannary 14th, 1920 at 8 p.m. The vermiform aypendix wes gangrenous throughout, and so rotten that it ruptured during its extraction.

\section{Acute Intestinal Obstruction.}

The causes of intestinal obstruction are similar to those which cause obstruction in all the tubular structures of the body. It may be produced by obstacles (1) outside the tube, (2) in its wall, (3) in its lumen, (4) by displacements of the tube itself.

'The diagnosis of intestinal obstruction is based upon a trinity of signs: (1) Severe spasmodic pain, (2) evidence (visible, audible, or palpable) of increased peristalsis, (3) inability to pass flatus per anum. In acute cases persistent and frequent vomiting is valuable additional evidence.

When these symptoms are present the first thing to do is to examine the hernial sites with the greatest care, because a strangulated hernia is the most common cause of intes tinal ebstruction. It is one still too often neglected, if the patient has overlooked the presence of a hernia, or has attached no importance to the swelling.

In the early stage shock is most pronounced when a considerable loop of gut has become acutely strangulated by a tight band or collar, and may continue till gangrene develops, when the reaction stage commences. It is not yet realized how deceptive the appearance of rccovety of patients with gangrenous intestine may be.

The treatment of intestinal obstruction is still one of the black spots in our work, because delay follows on diagnostic difficulties, and dangerous changes occur with such serious rapidity as to make prompt action essential to success.

'The differential diagnosis of cases of intestinal obstruction nay be as difficult as that of other abdominal lesions. It is occasionally helpful to remember that in clildren intussusception is the most common cause; in adults, bauds from adhesions due to healed tubercle, or the results of appendicitis, or past operation, or remnants of Meckel's diverticulum; and in elderly patients malignant strictures, especially of the colon. In addition to examination of the lernial sites, an examination of the rectum should never be omitted if humiliating mistakes are to be avoided.

A colonred drawing showing the serious condition of bowel six Lours after aente strangulation was exhibited.]

Cass II.-Acute Intestinal Obstruction duc to Adlzesion to old 'Tubereulones Alesenteric Gland.

This man, aged 22, admitted January 13th, 1920, had had a pain in his abdomen on Sunday evening (January 11th, 1920). I doutled him up all niglit, but he got some relief from hot fomentations and pressing his hands into his belly.- Two hours after the pain vomitios came on, and it never ceased till his admigion on the following Tuesday evening at 7 o'clock. After the pain commenced ho had passed no wind or motion. but on Yonday morning heard rumbling, and could feel something rolling in his belly. He was seen by a doctor on Monday and got some modicine, but vomited it all. He seys he toll the dootore then about the rumbling and his guts rolling round. The doetror saw him acain on Tuesday afternoon and ordered him to to the infirmary at once. On admission he was in 8 condition of shock. Pulse 112, temperature $98^{\circ}$, respirations 36 . He vomited yellow faecal-smelling fluid. His abdomen was somewhat distended, rigid and tender in the centre. $A$
peristaltic wave could be seen and felt in a line above the peristaltic wave could be seen and

umbiticu and passing to the left. A disemosis of acate in

Operation ghowed acut e cistension of the upper four leet of ejunum and an obstruction due to adhesion of intestine to an old tuberculons gland in the mesentery. A lateral anastomosis of disteuded gut above and contracted below was made.

He could not say whether he had any abdominal illness as a child. Two years ago he had a pain similar to this one, but it only lasted six hours. 
Perforation of the -Stomach and Duodenum.

There is abundant evidence for the view that these serious lesions may undergo a natural cure, but this must not be offered as an excuse for delay in their treatment, because they still rank as the most dangerous of the abdominal einergencies.

Simple ulcer of the stomach or duodenum is the recog nized cause of the greatmajority of perforations, and if they can be satisfactorily closed before the leaking contents have widely infected the peritoneum, recovery is almost a certainty.

A history of previous "indigestion" is obtainable in the great majority; then comes a sudden overwhelming pain. In duodenal cases the intestinal contents, loaking into the subhepatic pouch, escape down the gutter on the outer side of the ascending colon and caecum into tho pelvis, and may cause the chief pain, tenderness, and rigidity to be referred to the right iliac fossa. This accounts for the frequency with which such cases are sent with a diagnosis of appendicitis. Mistakes will be less frequent if a history typical of duodenal ulcer is available, and if the sudden overwhelming onset receives due consideration.

[Photograplis of specimens of ruptured gastric and duodenal ulcers were shown.]

CASE III.-Ruptured Gastric Ulcer

This youth, aged 17 years, was admitted January 8th, 1920. Ho brought with him the following note from his doctor:

\section{Dear Sir,}

I hops that you will admit F. C., aged 17 years. Diagnosis isRuptured gastric ulcer.

History.-The patient has been troubled with slight dyspepsia (ho describes it as a sickly pain, though he never vomited, coming on about two hours after food) for the last three weeks. At 6.50 thi evening, when at work, he was suddenly seized with severe abciomina pain. He attempted to walk home, but when he got half way wa found by a lady standing leaning against a pole and groaning with pain. The lady helped him home, and got

I saw the patient at 8 p m. He was lying on his back groaning with pain. He was very pale, cold, and c llapsed. Pulse 112, and ver. faint; temperature $95.6^{\circ}$. His abdomen was as hard as a board on examination and very tender. Liver dullness present. Breathing was thoracic in character.

Yours truly,

The patient was driven to the infirmary, well packed with blankets and hot-water bottles, in an ambulance, for six miles. On admission he was in good condition. Skin warm, pulse 75 of good volume. There was board-like rigidity of the whole. abdomen.

Operation (five hours after perforation) showed a leaking ulcer on the gastric side of the pylorus. This was closed by pyloroplasty through the ulcer.

\section{Gall Stones and Cholecystitis.}

It is not sufficiently recognized that if a gall stone suddenly blocks the neck of an infected gall bladder, conditions of great danger may quickly develop. A distended inflamed gall bladder in the course of twenty-four hours may becorne gangrenous, and the patient seriously ill. Unless quickly relieved by operation, rupture of the gall bladder allows of the discharge of its infected contents into the peritoneum, and peritonitis, likely to be fatal, results. Diagnosis is based upon the previous history of gall-stone attacks, but cliefly on the discovery of a hard, teuder rounded lump in the position of the gall bladder under the right costal margin. [A coloured drawing of a gangrenous gall bladder with stone impacted in its neck was shown.]

Ovarian Cyst with Twisted Pedrcle.

In women this is a common cause of an abdorninal omergency. If the tumour has been previously recognized, or is evident on examination, and a sudden attack of abdominal pain has developed with tenderness and enlarge. ment of the lump, it is probably due to torsion of the pedicle of an ovarian cyst. In the majority of instances a serious attack has been preceded by one or more minor seizures-which have left the patient apparently little the worse. In serious attacks the vascular supply of the tumour is interfered with, and gangrene of the tumour and peritonitis are the terminal results. [A drawing of an ovarian cyst with twisted pedicle was exhibited.]

\section{Ectopic Gestation.}

Another serious abdominal emergency peculiar to women is caused by intra-abdominal haemorrhage, due to rupture of an ectopic gestation.
In the most dangerous variety of this lesion diagnosis has to be made chiefly upon the signs of internal haemorrhage. An early impregnated ovum has eroded through the Fallopian tube, usually close to the uterus, and such furious haemorrhage follows that life can only be saved by operation.

In the more common variety one or two periods have been missed and the patient suspects that she is pregnant. The first warning that all is not right arises from a sudden attack of pain, which may be repeated once or more before the fival rupture (Case Iv). This pain is probably due to colic of the tube in its endeavour to expel the impregnated ovum. At this stage vaginal and bimanual examination can discover the distended tube at one side of or behind a uterus which offers evidences of pregnancy, and examination of the breasts may support this suggestion. If left alone the patient is suddenly overwhelmed by pain; and the symptoms of internal haemorrhage more or less quickly develop. . In many the loss of blood has been so great as to allow of an additional sign-shifting dullness in the flanks- to be discoverable before operation.

Some of the most wonderful resurrections due to surgery have been obtained by operation in these cases, and deatl following it has been rare, except when the patient was already moribund before the abdomen was opened.

Case IV.-Ruptured Fallopian Pregnancy.

This married woman, aged 29, was admitted January 14th, 1920. Four days before she was suddenly seized with pain in the lower part of the belly, "worse than labour pain." She felt at once very ill, the pain " went up to her heart," and made her feel as if she would die. She vomited several times.

On admission she was very ill, pale and anaemic, with dirty tongue, and was complaining chiefly of rectal tenesmus. (This is a common symptom in ectopic gestation.) There was a tender lump in the right iliac region with some rigidity.

Previous History.-'T'wo children, elder 10 , younger 8 years.
-

Previous History. Two children, elder 10, younger 8 years.
Never well after last labour. Menstruation irregular, seldoni Never well after last labour. Menstruation irregular, seldom a week without haemorrhage till four months ago. Then haemorrhage ceased for five weeks. Two months ago ahe thought she must be pregnant because her breasts swelled and attack of pain which lasted for two or three hours and made her feel faint. The pain was accompanied by free haemorrhage and the discharge of a "skin." 'I'his pain had been repeated several times before the final attack (examination then would have discovered a tubal swelling). She had consulted three doctors, but was not examined till her final seizure, when the condition was correctly interpreted.

On opening the abdomen, it was found to be distended with blood and clot, and there was a pregnancy in the right Fallopian tube.

RGFenkncF.
${ }^{1}$ See Triple Syndrome in Abdominal Emergencies, Britran Medical JOURNAL, January 3rd, 1914.

\section{REMARKS ON THE ASSOCIATION OF AORTIC ENDOCARDITIS AND AORTITIS.}

J. E. MacILWAINE, M.D., B.Sc., D.P.H.

PUYSICIAN IN CHARGE OF OUT-PATIENTS, ROYAL VICTORIA HOSPITAL, BELFAST.

In bringing forward this subject my object is to allow the members of the Branch to see two morbid specimeus which we have been recently fortunate enough to secure. I would like to acknowledge my indebtedness to Dr. Boyd Campbell who has been associated with me in studying these cases, and who has taken the notes and made all tho blood examinations.

For a considerable period it has been my experience to see a number of genuine endocarditic lesions of the aortic valve where clinical evidence seemed to point to the fact that the myocardium was not the important consideration in prognosis and treatment. I liave had the advantage of making an electro-cardiographic examination in practically all the cardiac patients I examined, and this method added in some cases a considerable weight of evidence for the conviction that myocardial change was not in itself at all sufficient to endorse the gravo prognosis which evidently the general condition of the patient demanded.

After reading Sir Clifford Allbutt's wonderful contribution to cardiac literature in his work on arterial disease, ${ }^{1}$ it

* Read before the Belfast Branch of the British Medical Association on F'ebruary 12th, 1920. 